\title{
Comparison of Chitosan Characterization from Mussel Shell Waste Using Varying Concentration of Solvents
}

\author{
Author \\ Nur Maulida Safitri (ORCID ID. 0000-0002-5326-3408), \\ Andi Rahmad Rahim (ORCID ID. 0000-0001-5514-6291), \\ Ummul Firmani (ORCID ID. 0000-0001-6816-8334) \\ Correspondence \\ Aquaculture Study Program, Faculty of Agriculture, University of Muhammadiyah Gresik \\ andirahmad@umg.ac.id
}

\begin{abstract}
:
Massive amounts of mussel shell waste are generated and wasted from the aquaculture processing sectors, resulting in environmental pollution. This material contains chitosan as a valuable compound characterized as a non-toxic structural component with several food processing applications or medicinal applications. In this research, mussel shells were processed using different solvents concentrations in several stages: demineralization, deproteination, decolourization, and deacetylation. Our result showed that the C2 samples gained a high degree of deacetylation $(31.8 \pm 0.21 \%)$ with low moisture and ash content and medium weight of yield. Further research is recommended to purify chitosan using various instrumentation and assess its bioactivity.
\end{abstract}

Keywords: Chitosan, Degree of Deacetylation (DDA), FTIR, Mussel Shell, Shell Waste

\section{Introduction}

Mussel shell waste is accumulated in massive quantities throughout the aquaculture processing industries and is discarded chiefly, resulting in severe environmental pollution. This waste considered a renewable resource or valuable compound, such as chitosan (Rashid et $a l, 2018)$. Shell waste is a significant source of chitosan, which accounts for about $40 \%$ of the dry weight of mussel shells (Hu et al, 2020).

Chitosan is a biopolymer composed of $\beta$ (1-4) D-glucosamine units synthesized chemically or enzymatically from the chitin. It is discovered as a structural component of bivalvia and other arthropods, which are biocompatible and non-toxic. As an industrial application, chitosan has various benefits, including food processing, feed supplement, agriculture, antibacterial goods, water treatment, and biomedical applications (Hart et al, 2020; Muthu et al, 2021).

Different solvents, incubation temperature and concentration, could influence the purity of the chitosan. Therefore, it could be feasible to remove more minerals and proteins from mussel shell waste by using a combination of acid and base, allowing more recovery of
Received: 14 July 2021. Accepted: 07 December 2021.

chitin to obtain a higher concentration of chitosan (Prameela et al, 2017).

The purpose of this research is to demonstrate a methodology for processing shell waste in order to extract chitosan and remove its contaminant. To determine the feasibility of our study, we examined chitosan powder using various solvents with varying incubation times and temperatures to get a higher level of chitosan purity.

\section{Material And Methods \\ Chitosan Extraction}

In general, synthesizing chitosan from mussel shell waste of Perna viridis is divided into four stages, namely preparation, demineralization, deproteination, and deacetylation; based on the method of Abdulkarim et al (2013) and modified method of Vairamani et al (2013).

Shells were cleaned in running water and then dried under the sunlight for 3-4 hours. The shells then were put in an oven at $40^{\circ} \mathrm{C}$ for $48 \mathrm{~h}$. Furthermore, the shells were crushed till smoothed and filtered through a sieve screen using mesh size $1 \mathrm{~mm}$. 
The demineralization stage was initiated by adding shell powder to $\mathrm{HCl}$ solution (w/v; $1: 5)$ with the concentration of $\mathrm{C} 1, \mathrm{C} 2$, and $\mathrm{C} 3$ were $0.68 \mathrm{~N}, 0.5 \mathrm{~N}$, and $1 \mathrm{~N}$, respectively.

This mixture was heated at $30^{\circ} \mathrm{C}(\mathrm{C} 1)$ and $40^{\circ} \mathrm{C}(\mathrm{C} 2-\mathrm{C} 3)$ for 24 hours with a constant stirring at $1500 \mathrm{rpm}$. The powder was then filtered and washed with distilled water to eliminate any residual $\mathrm{HCl}$.

The deproteination procedure is carried out by mixing demineralized samples with $\mathrm{NaOH}$ solutions at a concentration of $0.62 \mathrm{~N}$ at $30^{\circ} \mathrm{C}$ and $1 \mathrm{~N}$ at $80^{\circ} \mathrm{C}(\mathrm{C} 2-\mathrm{C} 3)$ with the ratio of sample mass (gr) and solution (ml) was 1:5. Continuous stirring at $1500 \mathrm{rpm}$ was performed for 24 hours. After separating the particles, the solid phase of the deproteination step was filtered and rinsed with distilled water to get the chitin fraction.

The resulting chitin then was subsequently deacetylated by adding $25 \mathrm{M}$ (C1) and $1 \mathrm{M}$ (C2-C3) of $\mathrm{NaOH}$ solutions, respectively. For $20 \mathrm{~h}, \mathrm{C} 1$ was heated to $40^{\circ} \mathrm{C}$, and $\mathrm{C} 2-\mathrm{C} 3$ were heated for $6 \mathrm{~h}$ at $110^{\circ} \mathrm{C}$ with the mass sample (gr) and solution (ml) comparison was 1:5. This mixture was continually stirred at $1500 \mathrm{rpm}$ and cooled at room temperature. Furthermore, this chitosan was rinsed with distilled water and dried for $24 \mathrm{~h}$ at $40^{\circ} \mathrm{C}$ to yield chitosan powder in $\mathrm{C} 1$.

In chitosan samples of $\mathrm{C} 2$ and $\mathrm{C} 3,10 \%$ of $\mathrm{CH}_{3} \mathrm{COOH}$ glacial was added and stirred at $1500 \mathrm{rpm}$ for 12 hours at room temperature. The solid phase then was washed twice with distilled water in $24 \mathrm{~h}$. The product was centrifuged at $1500 \mathrm{rpm}$ for ten minutes and dried to obtain chitosan powder.

\section{The Weight of Yield}

The weight of yield is the ratio between the amount (quantity) of chitosan generated from green mussel shells powder. The yield is expressed in percentages (\%). The yield weight was determined by calculating the percentage of chitosan extract (gr)/green mussel shells weight (gr) x $100 \%$.

\section{Degree of Deacetylation}

The spectra of chitosan samples were obtained using an I.R. Instrument (IR Spirit A22415801432, Shimadzu, Kyoto, Japan). The degree of deacetylation (DDA) in chitosan samples was calculated using baseline (a), which was proposed by Domszy and Roberts
(1985) in Khan et al (2002).

\section{Moisture Content of Chitosan}

The moisture content of the samples was measured by drying it in an oven at a temperature of $100-105^{\circ} \mathrm{C}$ for 3 hours. After cooling in a desiccator, it is weighed (gr).

\section{Ash Content of Chitosan}

The ash content was measured by burning the samples in an empty dish of the furnace at a temperature of $600-650^{\circ} \mathrm{C}$ until the sample was carbon-free, as indicated by the sample being greyish to white. The sample was then cooled overnight in a desiccator and weighed (gr).

\section{Results and Discussion}

The extraction of chitosan is accomplished through the deproteination method, which involves eliminating proteins using an alkaline solvent of $\mathrm{NaOH}$. The demineralization process follows the deproteinization method to remove the minerals contained in the $\mathrm{HCl}$ solvent. According to Arif (2006), the mineral content of animals is high. The majority of molluses had $\mathrm{CaCO}_{3}$ and $\mathrm{Ca}_{3}\left(\mathrm{PO}_{4}\right)$. The demineralization stage produced $\mathrm{CO}_{2}$ gas by the creation of air bubbles during the process. The depigmentation process alters the colour of chitin from brown to brownish white. Chitosan then was produced from chitin after a high concentration of $\mathrm{NaOH}$ was added into the samples for the chitin deacetylation process. The mixture then was washed with distilled water to remove any solvent after added with $\mathrm{CH}_{3} \mathrm{COOH}$ glacial $(\mathrm{C} 2$ and $\mathrm{C} 3)$.

Results show that all extracted chitosan samples were white colour \& powdered; All samples had a similar colour to the purified standard of chitosan. The weight of yield from extracted chitosan using various solvents was shown in Figure 1. The extracted $\mathrm{C} 1$ had the highest quantity with the percentages $39.21 \pm 0.36 \%$, while extracted C2 and C3 had $22.1 \pm 0.29 \%$ and $19.89 \pm 0.25 \%$. This figure indicated that the chitosan fraction obtained by chemical method without additional $\mathrm{CH}_{3} \mathrm{COOH}$ glacial in $\mathrm{C} 1$ sample was presented the highest yield. According to Djaeni et al (2003), prolonged operation time could result in a higher yield of chitosan products. It is induced by the extended contact time between chitin and $\mathrm{NaOH}$, which increases the conversion of acetyl groups in chitin to sodium acetic. 


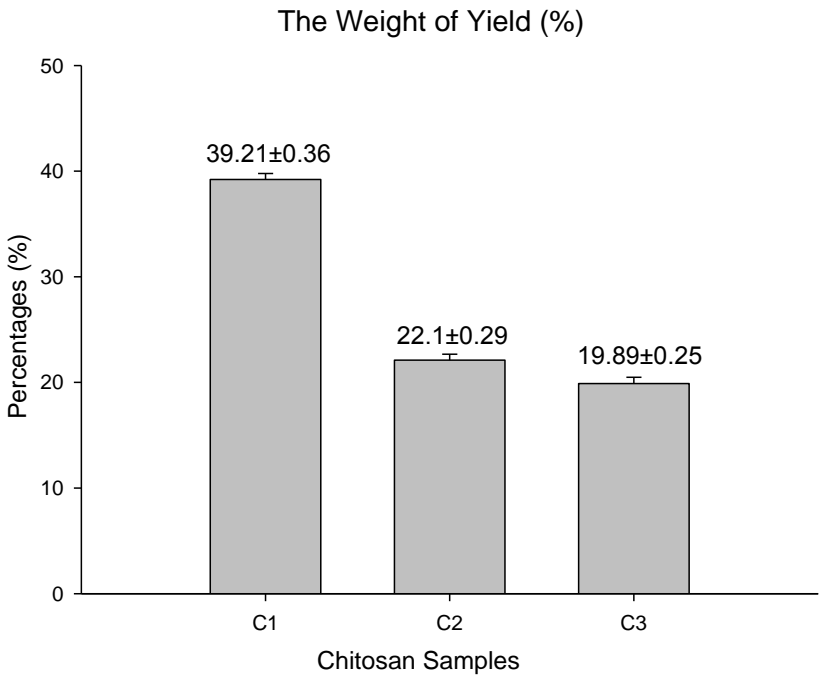

Figure 1. Chitosan yield (\%) from green mussels shell using various solvents

Regarding chitosan characterization, the deacetylation degree (DDA) is a critical parameter that characterizes their application. The DDA of $\mathrm{C} 1$ to $\mathrm{C} 3$ in a row were $28.2 \pm 0.4 \%$; $31.8 \pm 0.21 \%$; and $24.9 \pm 0.67 \%$, with the highest percentage was in C2 (Figure 2 ). Although $\mathrm{C} 1$ gave higher chitosan yield by prolonged operation time, the deproteination and deacetylation stage used much lower temperature, indicating lower chitin and its deacetylation results. According to Huang et al (2002), the intake temperature of active substances utilized in chitosan preparation ranges between 120 to $170^{\circ} \mathrm{C}$. The fluid containing chitosan is subjected to high temperatures for a relatively brief amount of time to increase the chitosan product.

Szymańska and Winnicka (2015) also noted that using high temperature, the enormous surface area of the chitosan exposed to a heat stream could lead to a more significant concentration of hydrolysis products on the surface particles and faster agglomeration. However, this condition was vulnerable to thermal degradation and change of the physicochemical properties of the polymers.

Another crucial factor in chitosan extraction was maceration time. Although longer operation time $(\leq 24 \mathrm{~h})$ could enhance chitosan yield, nevertheless, more than 3 hours, the optimization process could not improve the chitosan yield; even it could reduce the product (Romero et al, 2018). This result is because the acetyl group content of chitin decreases. As a result, large concentrations of $\mathrm{NaOH}$ would introduce the chitin component, causing its chitosan product to be degraded.

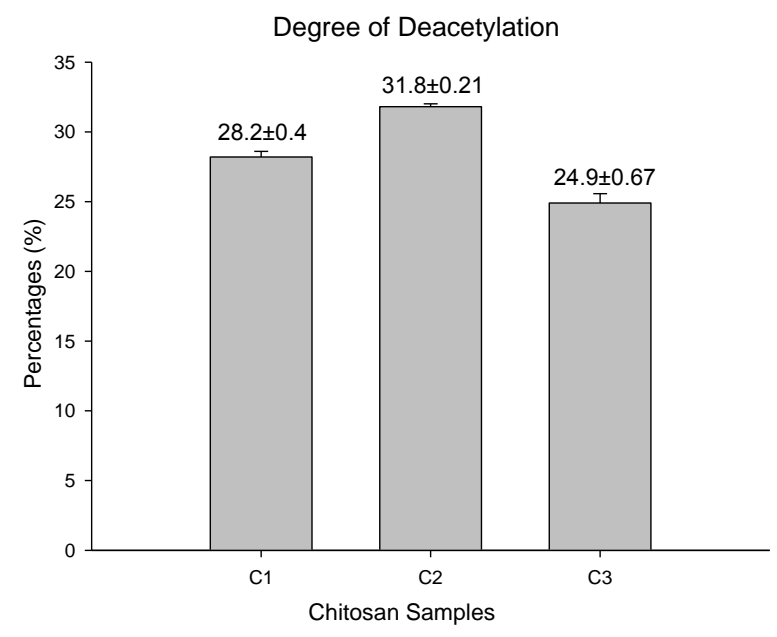

Figure 2. DDA (\%) from green mussels shell using various solvents

The concentration of $\mathrm{NaOH}$ regulates DDA of chitosan. The acetyl groups bonded in chitin were extremely tough to be removed. To improve the quality of the chitosan, a high concentration of $\mathrm{NaOH}$ and a high temperature are required (Moosa et al, 2016). Although using different concentrations and temperatures, DDA of $\mathrm{C} 1$ to $\mathrm{C} 3$ were not significantly different. According to Djaeni (2003), it needs an optimal concentration and temperature of $\mathrm{NaOH}$ during the deacetylation procedure. Too high a concentration of $\mathrm{NaOH}$, the chitosan product could decrease. This phenomenon is caused by using an excessively high dose of $\mathrm{NaOH}$ to remove acetyl groups from chitin. As a result, the residual $\mathrm{OH}$ - will attack the chitin ring, causing the chitin complex to degrade.

However, when the concentration of $\mathrm{NaOH}$ is reduced by less than $20 \%$, the interaction between $\mathrm{NaOH}$ and acetyl groups cannot continue because the $\mathrm{OH}$ - concentration is insufficient. These findings were consistent with Hossain \& Iqbal (2014) results. Using different concentrations of $\mathrm{NaOH}(40-80 \%)$ would optimize the deacetylation process, with the deacetylation grade reached $73.4 \%$ at $\mathrm{NaOH}$ concentration was $60 \%$.

The addition of $\mathrm{CH}_{3} \mathrm{COOH}$ glacial in $\mathrm{C} 2$ and $\mathrm{C} 3$ aims to increase the deacetylation process of chitin to chitosan. The protonation of $\mathrm{NH}_{2}{ }^{+}$of chitosan in acidic media allowing the chitosan polymer to work as a thickener or suspending agent. It is also noted that acetic acid would increase its solubility (Thomas et al, 2015). When combined with acetic acid, chitosan improves gelation and drug entrapment in the sol-gel method (Essel et al, 2018). This method resulted in higher solubility of $\mathrm{C} 2-\mathrm{C} 3$ than $\mathrm{C} 1$ due to additional $\mathrm{CH}_{3} \mathrm{COOH}$ glacial at the end of the process. 


\begin{tabular}{llll}
\hline No & Wave number $\left(\mathbf{c m}^{-1}\right)$ & \multicolumn{1}{c}{ Possible assignment of functional groups } & Nature of peaks \\
\hline 1 & 3435.74 & H-bonded $\mathrm{NH}_{2}$ \& $\mathrm{OH}$ Stretching & Broad \\
2 & $2983.63-2855.28$ & Aliphatic $\mathrm{CH}$-stretching & Medium \\
3 & 1787.04 & Amide C=O stretching & Sharp \\
4 & 1457.59 & NH Bending & Broad \\
5 & 1082.49 & C-O-C stretching & Sharp \\
6 & $861.43-711.68$ & C-N stretching & Sharp \\
7 & 509.16 & C-O Bending & Medium \\
\hline
\end{tabular}

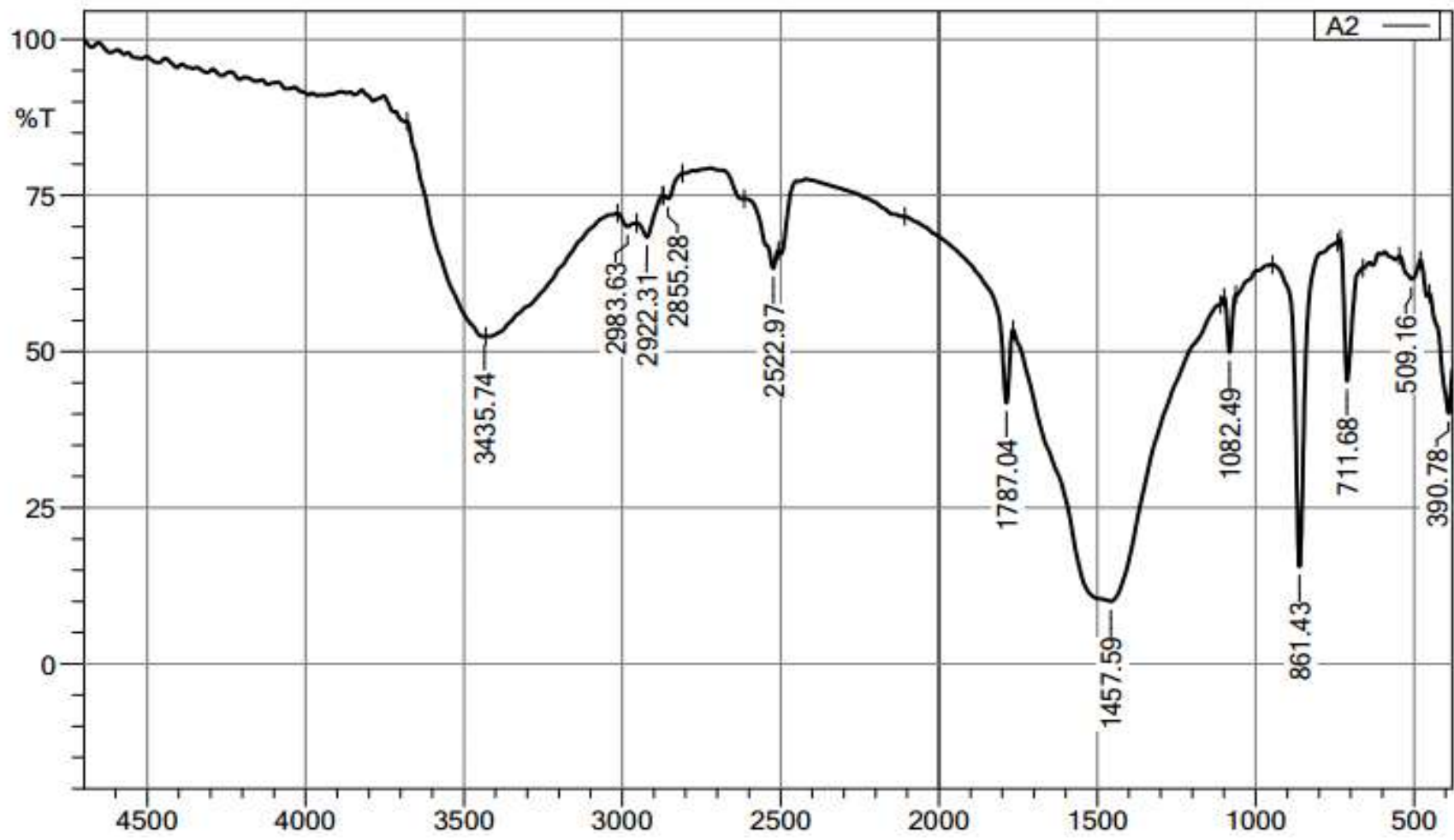

Figure 3. FTIR Spectra $\left(\mathrm{cm}^{-1}\right)$ of green mussels shell C3

The FTIR spectrum of chitosan on all samples has a chitosan functional group in a similar wavelength, indicated that the chitosan fraction was successfully extracted from shell mussels of $P$. viridis (data were not shown). In C3 chitosan, broad peaks were seen in the FTIR spectra of chitosan at $3435.74 \mathrm{~cm}^{-1}$ were $\mathrm{H}$ bonded $\mathrm{NH}_{2}$ \& $\mathrm{O}-\mathrm{H}$ stretching functional groups. Medium peaks were seen in 2983.63, 2922.31, and $2855.28 \mathrm{~cm}^{-1}$ were aliphatic $\mathrm{CH}$-stretching. A sharp peak of amide $\mathrm{C}=\mathrm{O}$ stretching was seen at $1787.04 \mathrm{~cm}^{-1}$. A broad peak of NH bending was seen at $1457.59 \mathrm{~cm}^{-1}$. Another sharp peak of CO-C stretching was seen at $1082.49 \mathrm{~cm}^{-1}$. At 861.43 , and $711.68 \mathrm{~cm}^{-1}$ were identified as $\mathrm{C}-\mathrm{N}$ stretching, shown as sharp peaks. Lastly, C-O bending \& ring stretching was shown at 509.16 $\mathrm{cm}^{-1}$ with a medium peak. Using another mussel from horse mussel Modiolus modiolus

FTIR spectra of chitosan by Varma and Vasudevan (2020) revealed vibrational mode of
$\mathrm{O}-\mathrm{H}$ stretching at $3594 \mathrm{~cm}^{-1}, \mathrm{CH}_{2}$ stretching at $2865 \mathrm{~cm}^{-1}$, amide C-O stretching at 1604, 1598, and $1592 \mathrm{~cm}^{-1}, \mathrm{C}-\mathrm{O}-\mathrm{C}$ stretching at $1174 \mathrm{~cm}^{-1}$, $\mathrm{NH}$ bending at $711 \mathrm{~cm}^{-1}$, and $\mathrm{C}-\mathrm{O}$ bending at 564 $\mathrm{cm}^{-1}$. Similarly, FTIR spectra of shrimp shells waste gave characteristic bands of $\mathrm{NH}_{2}$ and $\mathrm{O}-\mathrm{H}$ stretching at $3425.58 \mathrm{~cm}^{-1}, \mathrm{~N}-\mathrm{H}$ stretching at 3271.27, symmetric $\left(\mathrm{CH}_{3}\right)$ \& asymmetric $\mathrm{CH}_{2}$ stretching at $2924.09 \mathrm{~cm}^{-1}, \mathrm{C}=\mathrm{O}$ in the $\mathrm{NHCOCH}_{3}$ group (amide I band) at $1654.92 \mathrm{~cm}^{-}$ ${ }^{1}$, Amide II band at $1558.48, \mathrm{CH}_{2}$ bending $\& \mathrm{CH}_{3}$ deformation at $1423.47 \mathrm{~cm}^{-1}, \mathrm{C}-\mathrm{O}$ stretching at 1033.85, and ring stretching at $894.97 \mathrm{~cm}^{-1}$ (Moosa et al, 2016).

The moisture content of chitosan in all samples was shown in Figure 4, in the range of $5.58 \pm 0.61$ to $7.87 \pm 0.47 \%$. This water content is still appropriate to use as the standard chitosan has less than $8 \%$ moisture content. This result indicated that various concentrations of solvents did not affect the water content of chitosan 
significantly. Lower percentages of moisture content would keep chitosan dry and minimize the microorganisms in the samples. This result also indicated that the drying time and temperature were optimized to minimize the moisture content of chitosan.

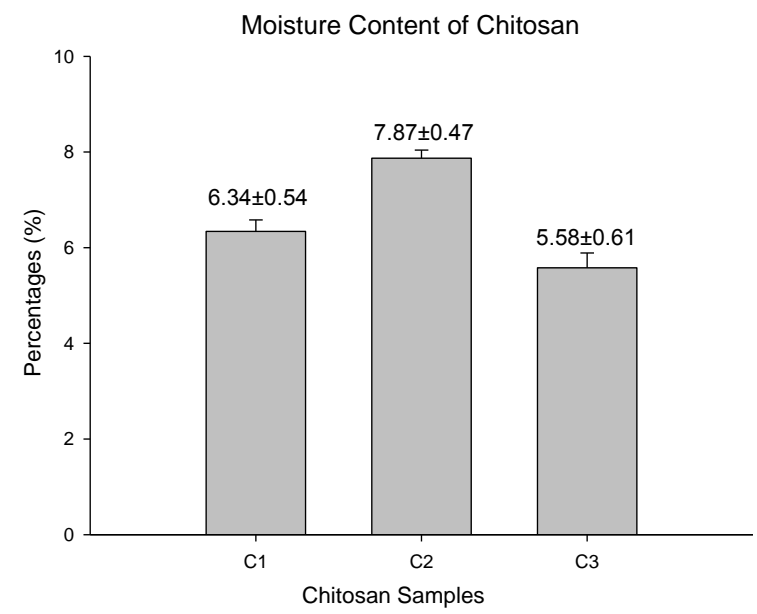

Figure 4. Moisture content (\%) from green mussels shell using various solvents

The ash content of all chitosan samples was shown in Figure 5. The ash content was ranged from $50.39 \pm 0.5 \%(\mathrm{C} 2)$ to $66.79 \pm 0.38 \%$ (C1). Kurniawan et al (2019) studied the effect of $\mathrm{HCl}$ concentration on the demineralization process of chitosan shell crab. Different concentrations of $\mathrm{HCl}(1-1.5 \mathrm{M})$ resulted in different demineralization effectiveness. The smaller the $\mathrm{HCl}$ solvents, the greater chitosan purity produced.

The high ash content in this research, especially on $\mathrm{C} 1$ and $\mathrm{C} 3$ was attributed to an inefficient demineralization concentration and stirring throughout the extraction and washing process. Furthermore, mixing $\mathrm{HCl}$ solution with shells powder stage needs to be added gradually to minimize the bubbles $\left(\mathrm{CO}_{2}\right.$ gas) that minimize the demineralization process. A poor washing procedure will result in released minerals that may be reattached to the surface of the chitin molecule. Minerals that have been liberated from the substance were bonded to the solvent and discarded and dissolved with the water. This result also could impact the ash content of the chitosan. The constant stirring would perfectly distribute the solvent could bind the minerals perfectly (Avadi et al, 2004).

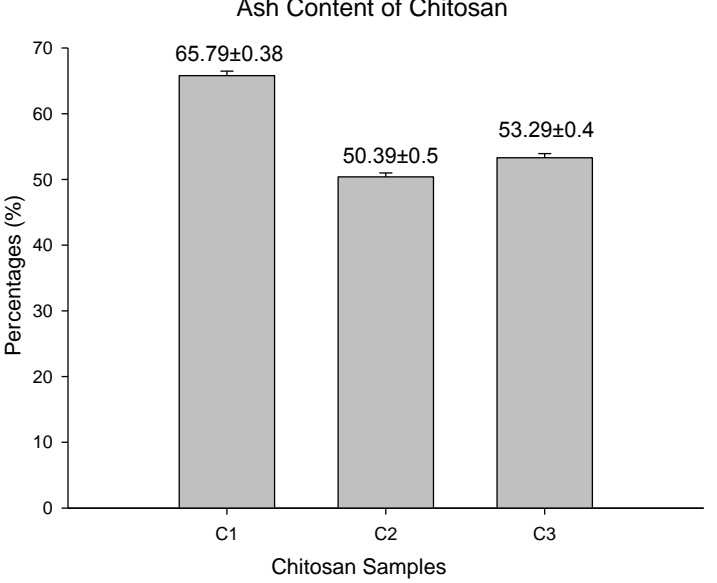

Figure 5. Ash content (\%) from green mussels shell using various solvents

Higher ash content was linear with a lower chitosan deacetylation degree. In our result, the $\mathrm{C} 1$ sample had a high percentage of ash content and chitosan yield, contrary to the degree of deacetylation percentage. Otherwise, in another sample of $\mathrm{C} 2$, although the ash content was still high due to extraction procedure and solvent concentration, its deacetylation degree and the weight of yield were still higher than other samples.

Thus, according to our research, $\mathrm{C} 2$ has the optimum condition to gain better chitosan quality from shell mussels waste. Several factors must be addressed throughout the chitosan process, including a lower concentration of $\mathrm{HCl}$, middle (40-60\%) concentration of $\mathrm{NaOH}$, high temperature with shorter maceration time, additional of $\mathrm{CH}_{3} \mathrm{COOH}$ glacial to increase deacetylation of chitin, constant stirring during the whole extraction process, and high technique of washing procedure to gained purified chitosan.

\section{Conclusion}

This study was demonstrated the various chemical characterization of chitosan from mussel shell waste using different solvents concentrations. The optimal condition to extract chitosan is using $\mathrm{HCl} 0.5 \mathrm{~N}$ at $40^{\circ} \mathrm{C}$ in the demineralization stage, $\mathrm{NaOH} 1 \mathrm{~N}$ at $80^{\circ} \mathrm{C}$ in the deproteination stage, $\mathrm{NaOH} 1 \mathrm{M} 110^{\circ} \mathrm{C}$ for $6 \mathrm{~h}$ in deacetylation stage, and additional $\mathrm{CH}_{3} \mathrm{COOH}$ glacial $10 \%$ at room temperature. The resulting chitosan gained high deacetylation $(31.8 \pm 0.21 \%)$, low moisture and ash content, and medium weight of yield.

The FTIR spectra of chitosan were also identified as several functional groups, such as: 
H-bonded $\mathrm{NH}_{2}$ \& $\mathrm{OH}$ Stretching, Aliphatic CHstretching, Amide $\mathrm{C}=\mathrm{O}$ stretching, $\mathrm{NH}$ Bending, $\mathrm{C}-\mathrm{O}-\mathrm{C}$ stretching, $\mathrm{C}-\mathrm{N}$ stretching, $\mathrm{C}-\mathrm{O}$ bending, and ring stretching. Basic formulation of the DDA, the weight of yield, moisture and ash content, of the mussel shell waste can efficiently generate chitosan to be high yield. Further research is needed to increase chitosan purity using the different instruments (such as sonication) or implement this chitosan as an additional supplement to evaluate its bioactivity.

\section{References}

Abdulkarim, A., Isa, M.T., Abdulsalam, S., Muhammadi, A.J., and Ameh, A.O. 2013. Extraction and Characterization of Chitin and Chitosan from Mussel Shell. Civil and Environmental Research. 3(2): 108-115.

Arif A.R., Ischaidar., Natsir Hasnah., Dali Seniwati. 2013. Isolasi Kitin dari Limbah Udang Putih (Penaeus merguiensis) Secara Enzimatis. Seminar Nasional Kimia. Makassar. Hal. 1016.

Avadi, M.R., Mahdavia, G., Sadhegi, A.M., Erfan, M., Amini, M., Tehrani, M.R., and Shaflee,A., 2004. Synthesis and Characterization of $N$ Diethyl Methyl Chitosan, J. Iranian Polymer, 13(5): 431-430.

Djaeni, M. 2003. Optimization of Chitosan Preparation from Crab Shell Waste. Reaktor. 7(1): 37-40.

Hart, M. 2020. Mini-review of waste shell-derived materials application. Waste Management \& Research: The Journal for a Sustainable Circular Economy. https://doi.org/10.1177/0734242X19897812

Hu, X., Tian, Z., Li, X., Wang, S., Pei, H., Sun, H., Zhang, Z. 2020. Green, Simple, and Effective Process for the Comprehensive Utilization of Shrimp Shell Waste. ACS Omega. 5: 1922719235.

Huang Y, Yeh M, Chiang C. Formulation factors in preparing BTM-chitosan microspheres by spray drying method. Int J Pharm. 2002 Aug 21;242(1-2):239-42. doi: 10.1016/s03785173(02)00164-3. PMID: 12176254

Kurniawan, A., Hidayat N., Perdani, C.G. 2019. Effect of Particle Size and $\mathrm{HCl}$ on Chitosan Shell Crab Demineralization 56 Effect of Particle Size and $\mathrm{HCl}$ Concentration on the Demineralization Process Chitosan Shell Crab (Portunus pelagicus). Journal of Food \& Life Science. 3(2): 56-64.
Moosa, A.A., Ridha, A.M., Kadhim, N.A. 2016. Use of Biocomposite Adsorbents for the Removal of Methylene Blue Dye from Aqueous Solution. American Journal of Materials Science. 6(5): 135-146 DOI: 10.5923/j.materials.20160605.03

Muthu, M., Gopal, J., Chun, S., Devadoss, A.J.P., Hasan, N., Sivanesan, I. 2021. Crustacean Waste-Derived Chitosan: Antioxidant Properties and Future Perspective. Antioxidants. 10 (228): 1-27.

Prameela, K., Venkatesh, K., Vani, K.D., Kumar, E.S., Mohan, C.H.M. 2017. Eco-Friendly Extraction of Biopolymer Chitin and Carotenoids from Shrimp Waste. IOP Conf. Ser.: Mater. Sci. Eng. 225. 012266

Rashid, H.A., Jung, H.Y., Kim, J.K. 2018. Enhanced reutilization value of shrimp-shell waste via fed-batch biodegradation with higher production of reducing sugar, antioxidant, and DNA protective compounds. Fisheries and Aquatic Sciences. 21(33): https://doi.org/10.1186/ s41240-018-0109-9

Romero, LG., Pascual, S., Aragunde, H., Biames, X., Planas, A. 2018. Chitin Deacetylates: Structures, Specificities, and Biotech Application. Polymers. 10(352): 34-62.

Thomas, S., Soloman, P.A., Rejini, V.O. 2016. Preparation of Chitosan-CMC Blends and Studies on Thermal Properties. Procedia Technology. 24: 721-726.

Thomas Y.A., Koomson, A., Seniagya M.P.O, Cobbold G.P., Kwofie, S.K. 2018. Chitosan Composites Synthesized Using Acetic Acid and Tetraethylorthosilicate Respond Differently to Methylene Blue Adsorption. Polymers. 10(466): 1-13.

Vairamani, S., Subhapradha, M., Ramasamy, P., Raveendran, S., Srinivasan, A. 2013. Physicochemical Characteristics and Antioxidant Efficacy of Chitosan from The Internal Shell of Spineless Cuttlefish Sepiella inermis. Preparative Biochemistry and Biotechnology. 47(3): 696-716.

Varma, R and Vasudevan, S. 2020. Extraction, Characterization, and Antimicrobial Activity of Chitosan from Horse Mussel Modiolus modiolus. ACS Omega.5(32): 20224-20230. 